Bragdon, J. H. (1959). Ann. N. Y. Acad. Sci. 72, 845.

Bronte-Stewart, B. (1958). Brit. med. Bull. 14, 243.

Desai, J. C. \& Glover, J. (r96r). Biochem. F. 79, 3 IP.

Frederickson, D. S. \& Gordon, R. S. (1958). Physiol. Rev. 38, 585 .

Havel, R. J. \& Gordon, R. S. (x955). Circulation, 12, 485.

Keys, A. (1957). F. Amer. med. Ass. r64, 1912.

Myers, J. D., Olson, R. E., Lewis, J. H. \& Moran, T. J. (1957). Trans. Ass. Amer. Phycns, 7o, 243.

Olson, R. E. (1958). Perspectives Biol. Med. 2, 84.

Olson, R. F., Jablonski, J. R. \& Taylor, E. (1958). Amer. F. clin. Nutr. 6, i I I.

Olson, R. E. \& Vester, J. W. (rg60). Physiol. Rev. 40, 677.

Salt, H. B., Wolff, O. H., Lloyd, J. K., Fosbrooke, A. S., Cameron, A. H. \& Hubble, D. V. (rg60). Lancet, ii, 325.

Ways, P., Re ed, C. F. \& Hanahan, D. J. (1961). F. clin. Invest. 40, ro88.

\title{
Some aspects of physical and physiological individual variation
}

\author{
By Robert W. McCammon, Director, The Child Research Council, 4200 East Ninth \\ Avenue, Denver 20, Colorado, USA
}

\section{Introduction}

I would like first to thank the members of the Society for this opportunity to participate in the symposium on individual variation. The title of this paper was chosen deliberately to permit freedom of selection from a wide range of data, and then hedged with the first three words lest it give the impression that I would presume to attempt an exhaustive discussion of physical and physiological variation between individuals. In considering the assignment I decided that I should limit myself to those variations that are more clearly established and that I should confine my material to data from the Child Research Council. I hope this will not be interpreted as parochial disinterest in events outside my own small world. It is intended as a means of sharing some of the results of over 30 years of study of individual variation in the same group of subjects. We are indebted to many outside our study for information, for ideas and for stimulation, and this indebtedness grows greater with each succeeding year.

Fhysical and physiological variation between individuals cannot be separated realistically. Great muscle strength and endurance come with bulging biceps, gargantuan caloric intake produces the large waist line, and poor resistance to disease is rarely a companion of vigorous physical proportions. However, I shall discuss them as if they were separate, not so much for the sake of convenience as in an attempt to conceal my lack of knowledge about how physical variation produces differences in function and vice versa. The examples chosen are only some representatives of hundreds of variations that exist between individuals, some of them obvious and some more subtle. They are also related to findings in basically healthy, well-fed children of similar ethnic extraction and do not reflect variation due to disease or want.

Before undertaking any discussion of individual variation, it is important to understand the difference between variation and abnormality. Custom has established the pattern of much medical thinking in this respect. It is customary to obtain 
measurements from a group of subjects at various ages and stages of development and from these to establish a central trend of change and some measure of variation around that trend. The resulting table or graph usually shows a smooth curvilinear progression from one age to another which is almost always referred to as the 'group trend', the 'normal trend', the 'human pattern' or by some similar term carrying the implication that it represents what an individual should do if he is to be considered normal. Actually, such a graph can represent nothing more than the range of variation observed at each age, and the smoothness of the channels formed by connecting similar points in the range of variability does not magically convert those channels into some sort of pathway along which an individual must progress from age to age if he is to be considered healthy. Quite the contrary, with the multitude of genetic and environmental influences acting upon the individual, it is to be expected that crossing channels at times may represent optimal adaptation under given circumstances. The majority of healthy individuals show both departures from channels established from group measurements and departures from patterns they have previously established for themselves.

\section{Variations in physical growth}

Variations in physique and in physical growth are in general more striking between the sexes than between individuals of the same sex, though it is true that growth patterns in a population form a smooth continuum between the extremely masculine and the extremely feminine. At birth the differences in size and physical proportions that are so apparent between adult men and women are at a minimum, but they nonetheless exist. Differences in growth rates between the sexes which serve to accentuate the variation present at birth are manifest even in infancy. Fig. I, though representing the linear growth of a single boy and a single girl, can be used to demonstrate the expected sex differences. Starting at nearly the same point, the boy's rapid growth rate in infancy pulls his curve up above the girl's curve in the first few months of life, but the relatively abrupt slowing in the boy's growth results in junction of the curves at 6 years. For the next 3 years the girl and boy follow exactly the same line on the graph. This is the age psychologists refer to as the latency period because of its stability and lack of dramatic changes in personality, and for many aspects of physical and physiological measurements the same term is applicable for the same reasons. At about 9 years the first manifestations of secondary sex development of adolescence appeared in the girl, and simultaneously her rate of growth increased. The boy continued for 2 more years along the same growth line as previously before his adolescence began and his growth rate accelerated. The slightly more rapid growth rate in adolescence for the boy combined with the already slowing rate in the girl to produce another crossing of the growth lines at about 12 years 9 months. By this age, linear growth of long bones was nearly complete in the girl, leaving her only a minor increment of height. Rapid growth in the boy continued for the expected and significantly longer period, producing the familiar result of later attainment of mature stature and significantly greater adult height in the man than in the woman. 


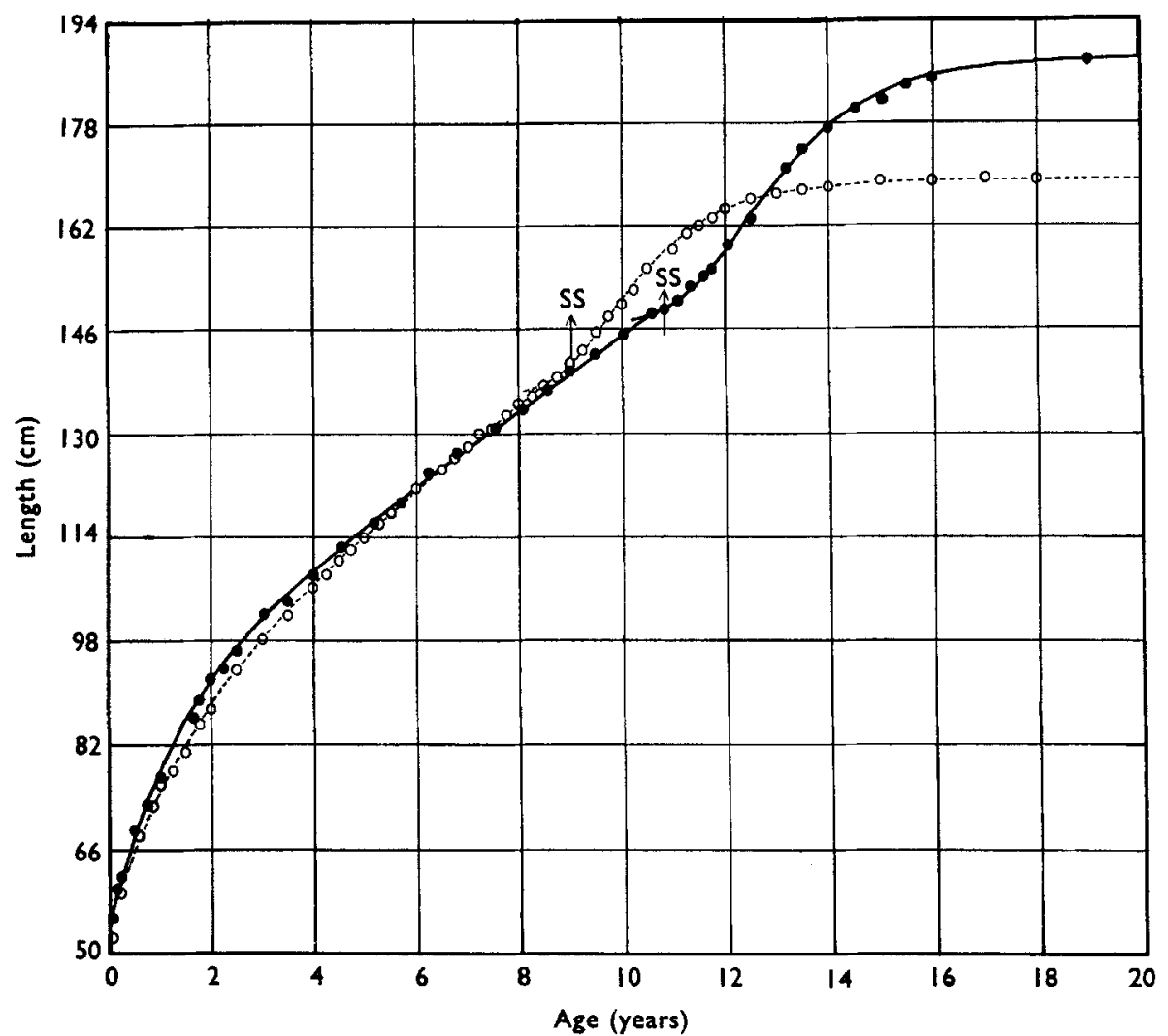

Fig. I. Linear growth curves of one boy and one girl from birth to maturity, illustrating sex differences in growth. - boy, A.H.; $\bigcirc--O$, girl, D.J.; SS, secondary sex development of adolescence.

The physiological concomitants of this linear growth are of interest. In the human being some unidentified influence prolongs the childhood growth pattern and with it all the manifestations of sexual maturation. There are two separate growth cycles, each definable by a mathematical equation applicable to both sexes, but no single equation has been devised to define both. It is as if two separate stimuli were operative which are mutually exclusive in time. It is convenient to think of the first growth cycle as being stimulated by the pituitary growth hormone and the second by gonadal hormones. The persistence of growth hormone in the same concentrations throughout life and the presence of at least some androgens from birth make this explanation manifestly an oversimplification, leaving us currently without adequate understanding of observed facts. In any event, the variations in growth between the sexes and between individuals of the same sex are in timing and in magnitude leaving the basic human pattern of linear physical growth comfortably invariant and mathematically expressable.

Dr Jean Deming, to whom I am indebted for these data, related a number of physiological and physical events to various portions of the adolescent growth curve (Deming, 1957). Fig. 2 shows some of these associations, including the close synchrony of the first visible evidence of secondary sexual development and the 


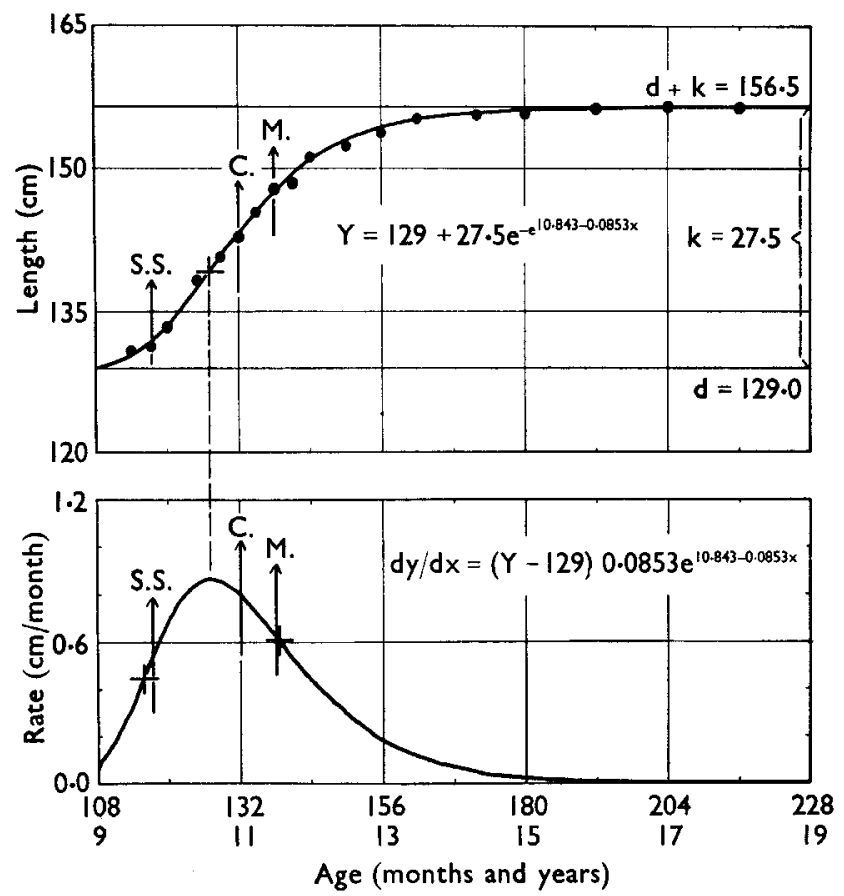

Fig. 2. Gompertz curve of linear growth in adolescence, and first derivative curve illustrating rate of one girl to show physiological concomitants of growth. SS, first visible evidence of secondary sex development; $C$, fusion of capitellum to shaft of humerus; $M$, menarche.

first inflection of the rate curve in adolescence, the fact that long-bone growth is always slowing before the menarche in girls, and the fact that the menarche occurs very near the time when deceleration in growth rate becomes less pronounced on the downward leg of a rate curve of adolescent growth. Dr Deming also investigated relationships between body size at various ages and such factors as age of onset of adolescent growth, maximum rate of growth during adolescence, and age of menarche in girls, without finding significant correlations.

Perhaps now is the time to discuss age of menarche. In our group of girls the variability so far observed for this event is from age 12 years 6 months to 15 years 4 months with a mean age of just over 13 years. This variation of 32 months between individuals is not attributable to ethnic or nutritional differences in the children and probably represents a reasonable portion of the variability that would be encountered in any group of healthy children. Today in the United States there is a widely held belief that modern youngsters are growing more rapidly and maturing earlier than their parents did 30 years ago. Not only do our data fail to support this belief, but Dr Edith Boyd, in her study (to be published) of man's knowledge of growth, has pointed out to us that the Greeks recorded a range and a mean not strikingly different from what we are observing.

Linear growth in the human being as measured by increasing height represents the sum of growth in several body segments. An adult height of a given magnitude can be composed of segmental lengths of considerable variability from one individual 
to another. Though the variations in physical proportions that result from this situation are not readily visible on inspection except in extreme instances, they may be of considerable importance in the functioning of the individual. As an example, a man of the same height as Roger Bannister who had relatively short legs and a relatively long trunk would be no rival to him in the mile run, and Dr Bannister would be at a disadvantage physically if he were to compete at wrestling with such a longtrunked opponent.

Edith Boyd reported an anthropometric study of changing body proportions during growth in one boy (Boyd, 1955) and Marion Maresh published a study of relative body proportions as represented by long-bone measurements in the four major bones of the extremities taken from X-ray pictures (Maresh, 1959). There is a great deal of material from these studies that cannot be presented, but a few striking findings should be mentioned. The infant already has well-differentiated proportions. That is, infants are no more alike in body build than are adults. Shifts in proportions within the individual are more common during the first 4 years of life than at any other age, and about $60 \%$ of individuals will shift position within the group during the span of infancy and early childhood. During the latency years from 4 to the onset of adolescence, proportions tend to remain constant, but with the onset of adolescence, shifts again take place. In more than two-thirds of a population there are shifts in proportions some time between early infancy and late adolescence. Thus, body build in infancy is not predictive of body build in the adult in the majority of people. Shift in relative proportions is small, with only about $15 \%$ of the group showing more change over the growing years than $40 \%$ of the group range. However, single segmental proportions in an individual may shift through considerably more than $40 \%$ of the range of variation seen between members of the group. The only consistent difference in proportions between the sexes is that males have relatively longer forearms than females, a fact long known to clothing manufacturers.

Studies of individual long-bone growth (Maresh, 1955) bring out many of the same facts that are found from a study of body proportions. Here again, shifts in position of an individual within the group distribution are most common in the first 4 years of life, uncommon in the latency years, and appear again during adolescence. Ordinarily there is less tendency for a bone length to change from one level to another in the children at the extremes in bone length. That is, very long bones tend to remain very long throughout the growth period and very short bones tend to remain very short. Between the extremes it is a rare child who does not show variability within the group in the length of at least one long bone at some time. Fig. 3 is a rectilinear graph of growth in length of the radius in four children from 2 months to 4 years, showing patterns of change in percentile position. The radius of child A grew much more rapidly than the group median for 15 months, then continued to 4 years at a slightly more rapid growth rate. Child $\mathrm{C}$ shows a progressive drop in position, child $\mathrm{D}$ a rise followed by a decline in position, and child $\mathrm{B}$ represents the children who remain at a constant level within the group. Similar graphs can be prepared for any of the long bones. The graph of percentile rank for the radius of a child does not bear any necessary relationship to a graph representing his humerus, tibia 


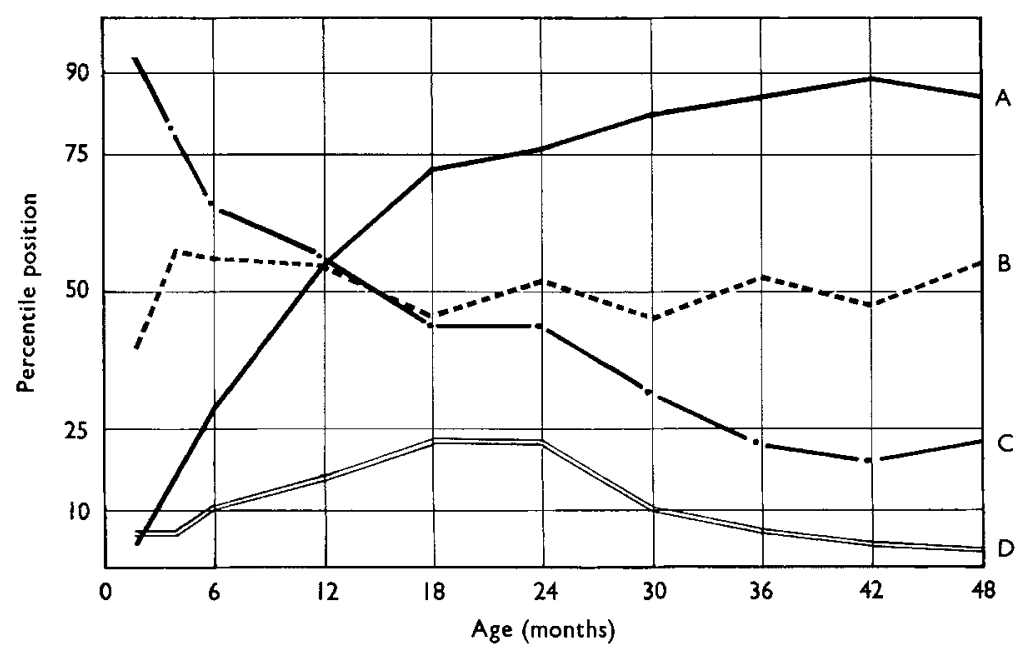

Fig. 3. Rectilinear graph of the growth in length of the radius in four children, A, B, C and D, from 2 months to 4 years.

or femur, although variations as wide as extreme shortness in one bone coupled with extreme length in another were not observed in any child.

Associations between childhood growth and adolescent growth and between childhood growth rate and age at adolescence have been investigated extensively and regression equations have been used to predict adult stature from size at various stages of childhood. Using such an equation to predict mature height from height at 6-7 years, Dr Maresh calculated adult heights for our group of children and compared them with measured heights. For half of the group, predicted and measured heights fell within $\pm \mathrm{I}$ in. of each other, which is quite adequate for most purposes. However, in the other half of the group, observed young adult heights were as much as \pm 3 in. from the predicted heights. For children who matured early the predicted height tended to be greater than the height they actually attained and for children who matured late it tended to be less. Again individual variation occurred and some individuals went against the trend, becoming taller than predicted in spite of early adolescence or being shorter than predicted even though they matured late.

Body composition is another factor in which individual variation reflects itself physically. A major difficulty in discussing the amounts of fat and of lean body tissues that are present and the variations that occur in them is that no accurate means of measuring body composition has as yet been devised. Such techniques as skinfold measurements and measurement of the width of bone, muscle and fat from X-ray pictures have the limitation that they do no more than to sample small parts of the body for those tissues that can be separated by the technique. Counts of radiation from total body ${ }^{40} \mathrm{~K}$ are more inclusive but difficult and expensive to obtain. Variation in the width of a tissue layer from one part of the body to another is found in most children and may be quite marked. In bone, the least variable tissue, it may amount to as much as I standard deviation above and below the mean for two bones in the same child. In muscle and fat even wider differences are observed. Considering the 
presence of such large differences at various levels of the body, our data do not support the frequently expressed belief that a single measurement taken from one part of the body is adequate to represent the tissue composition of the entire body (Maresh, I961). Measurements have not been completed and analysed in detail beyond 6 years of age, but indications are that this situation will be true throughout the childhood years.

An interesting observation regarding obesity in childhood was made during this study. Only one child who was regarded as a fat infant during the first couple of years of life retained that designation by the age of 6 years. Lean infants, on the other hand, sometimes remained that way. The change in the amount of fat present was not a gradual one over a period of years but tended to occur in 6-12 months at ages above 2 years. It seems unsafe, therefore, to make predictions of ultimate body composition from measurements taken at any time earlier than 6 years at least, and probably at any time in childhood.

We have made several attempts to relate fatness and leanness in our children to other data such as nutritional intake and basal oxygen requirements. In this, in any general sense, we have failed completely. The reasons for being fat are highly individual. Two girls selected for study because of weight problems represent both very high and very low caloric intake. One is a large, muscular, physically active child whose appetite is so enormous that she gets fat in spite of her activity. The other is a small girl with little interest in food and even less in exercise whose low intake cannot protect her from gaining. Even in such relatively clear instances as these, however, we are uncomfortably aware that we know nothing about genetic influences and are able to select only more obvious environmental and functional evidences of variation to include in our analyses. There can be no single prescription for the treatment of obesity in any age group, dietary and exercise enthusiasts to the contrary. Its causes are as variable as the habits, tastes, genes, and personalities of the people who suffer from it.

External and visible variations in physical build and in growth are not the only differences that occur. Pl. I is a reproduction of the chest plates of twenty boys at 8 years of age. Cardiac size varies from the small heart in no. 9 to the relatively enormous heart in no. 13 , and configuration from the round heart in no. I I to the tired-looking heart draped along the diaphragm in no. 7 or the apparently deformed heart in no. 19, all of which are in healthy children at age 8 who have stayed healthy into their early adult years. Cardiac growth as measured from the chest X-ray follows body-weight quite closely, and though the total body size does not predict accurately the size of the heart within the group range, we have not observed very large hearts in relatively light individuals or very small hearts in heavy individuals. Shape of the heart tends strongly to remain constant in the individual from early childhood, with succeeding pictures representing no more than increase in size (Maresh, 1948).

To demonstrate this variability between individuals and constancy within a single individual, Dr Maresh made up Pls. 2 and 3 a few years ago. Ages are given on the chest film reproductions and each plate represents a single child from infancy to maturity. Not only are the cardiac silhouettes the same from age to age except in 
size, but also the lung markings remain constant. Pl. 2 is of a male whose lung markings at 32 years could be interpreted as representing fibrotic or infiltrative disease if it were not for the combination of known freedom from any pulmonary symptomatology and the fact that all markings are equally evident at 6 months. Pl. 3 presents selected chest $\mathrm{X}$-rays from I month to 20 years in a girl whose lungs are quite clear at all ages and yet whose health history is no more free from infection than that of the boy in the preceding plate.

Skeletal maturation represents a sort of middle ground between the physical and the physiological. It is controlled apparently by many of the same physiological mechanisms that govern physical growth, but its course is not necessarily parallel to increasing body size. Methods for assessing it are many and vary from relatively simple to enormously complex. None of them is absolute, and our radiologists have inclined toward the Greulich-Pyle Atlas because of its long availability and relative simplicity. A rating of 'bone age' should not be regarded as more than an estimate with \pm 3 months understood in it. Even with these reservations, variation

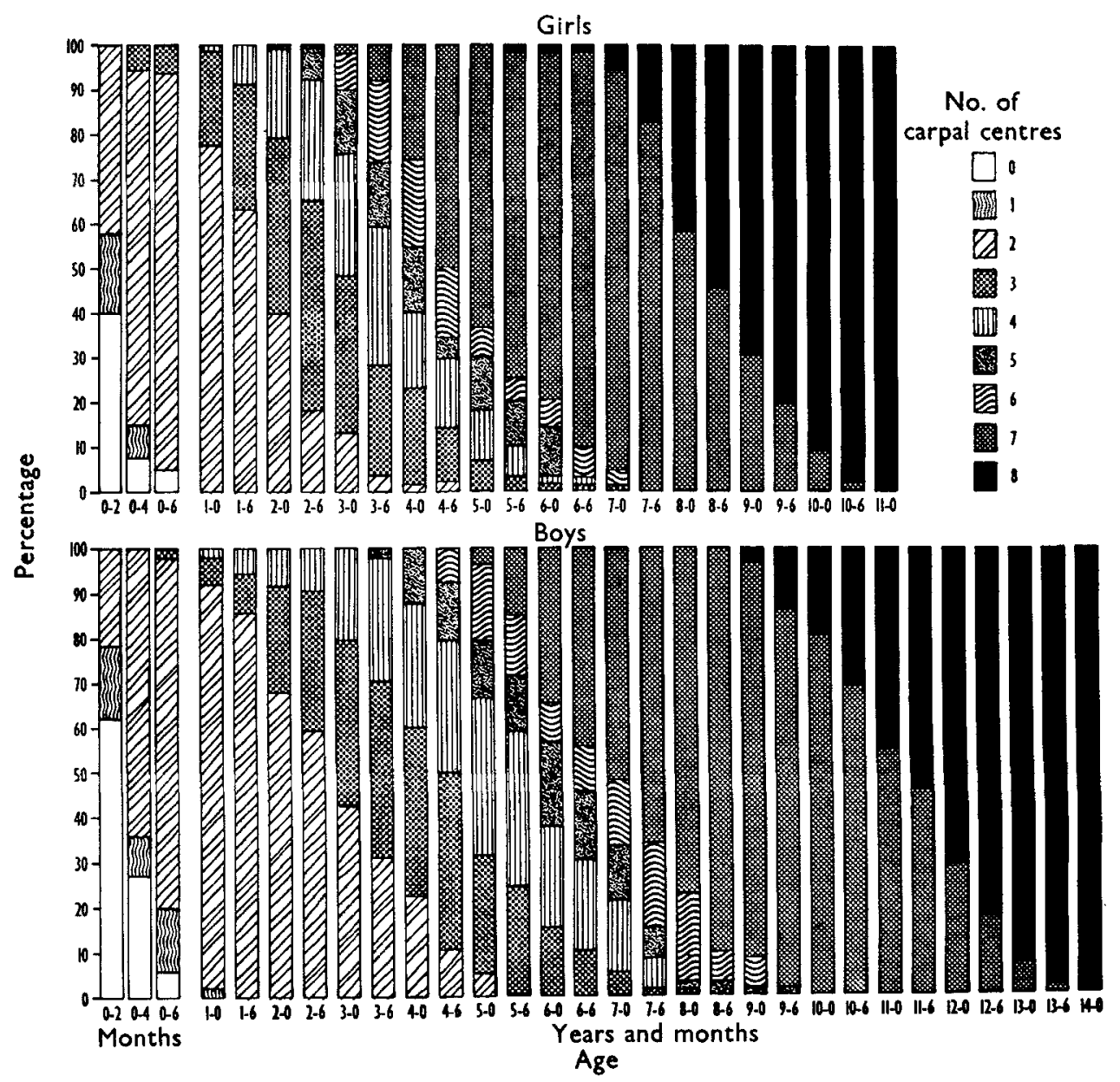

Fig. 4. Bar graph of the percentages of girls and boys who have visible ossification in various numbers of carpal centres at different ages. 
between individuals is wide. A detailed study of skeletal maturation has been reported for our group of subjects (Hansman \& Maresh, 1961). Of the many aspects considered, I shall mention only the age of ossification of the carpal centres as an example of individual variability. Fig. 4 is a bar graph of the percentage of girls and of boys who had visible ossification in a specified number of carpal centres at various ages. Sex difference is obvious, from such things as the fact that all girls show ossification of eight centres by II years of age, whereas boys reach this status first at 14 years. Variation between individuals of the same sex is most marked in boys at 5 years 6 months, when they range from two to seven centres present, whereas the girls show a range of six centres at most ages from 3 to 6 years. Ossification is another measurement in which individuals change from one part of the group to another, demonstrating the ability to vary the slowness or rapidity with which they progress in this measurement of maturation.

\section{Variations in physiological functioning}

Fig. 5 illustrates physiological manifestations of individual variability by presenting much data for three boys. The central line graph represents their scores on the

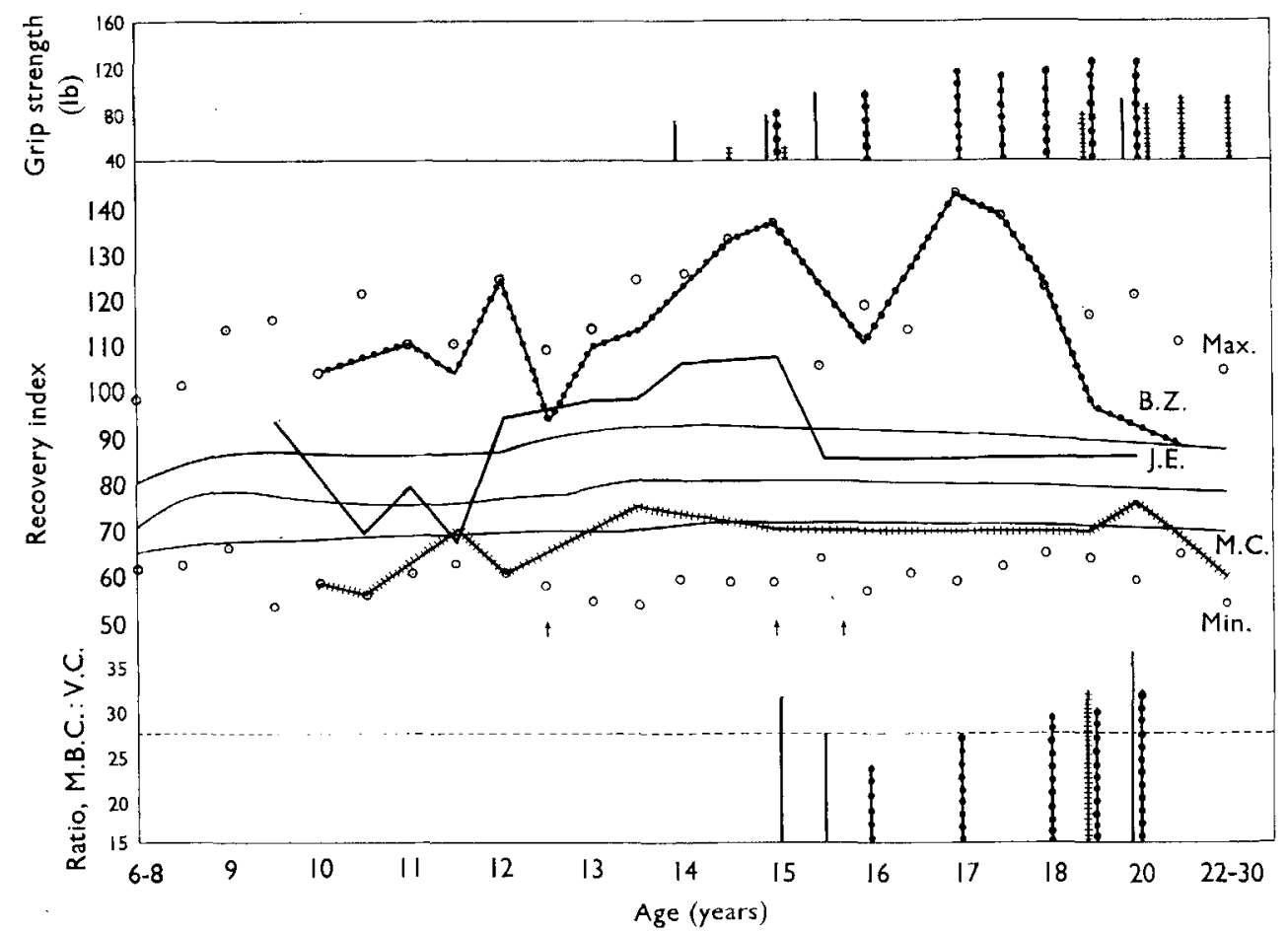

Fig. 5. Scores for three boys (B.Z., J.E. and M.C.) in tests of response to physical stress: grip strength (top), bicycle ergometer (centre) and ratio, maximum breathing capacity: vital capacity (MBC:VC) (bottom) at ages in childhood and adolescence. o, maximum (upper) and minimum (lower) scores for age; arrows, age of adolescent growth spurt.

bicycle ergometer test, a fairly standard measure of so-called 'physical fitness'. B.Z. is more often than any other boy the best in the group, J.E. is moderately good and M.C. is a poor performer. B.Z. is an athlete and the decline in his score 
after the age of 17 was synchronous with a decline in physical activity. Earlier drops have no such connotation, nor does the fact that he had two classical attacks of rheumatic fever with heart involvement before his first test and a third between $\mathrm{I} 3$ and 14 years of age manifest itself in his test scores. J.E. is what we call an individual athlete, since he was active in many sports but not in team endeavours. M.C. is best described as contentedly unfit. Thus, this measure separates these boys in the expected fashion, but if we look at the bar graphs of muscle strength at the top, the differentiation becomes less dramatic and, if we look at the representation of the ratio of maximum ventilation to vital capacity at the bottom, it is surprising to find the contentedly unfit boy showing a higher score than the confirmed athlete. In only three boys it becomes possible to demonstrate both variability in test results for each of three tests and variability in conclusions drawn as to their relative 'fitness' depending upon the measure used. It is possible thus to demonstrate that fitness improves with athletics and declines when they are stopped. By selection of other individuals it is possible also to demonstrate that sometimes 'fitness' declines with athletics and improves with their cessation and that fitness remains unchanged through periods of markedly different physical activity. What emerges from the consideration of data for many subjects is the highly individual pattern for a single subject which may or may not be constant for him from age to age. A further conclusion is that few persons are versatile enough to excel in all fitness tests. And, finally, there is suggestive evidence that genetic factors play important parts in determining the functioning of an individual as reflected in such tests (McCammon \& Sexton, 1958).

Inescapably, each individual is subject to infectious disorders and his ability to resist their invasion and overcome those he cannot resist is an essential part of his physiological functioning. Variability between individuals in these functions is remarkably wide, with respiratory infections the best area of comparison because they constitute the bulk of infectious disease in our group as they do in all other groups reported. The range of incidence of upper respiratory infection we have observed is from as few as none in an occasional child for a period of a year to as many as $12 /$ year for several successive years in another child. We see children who get many mild infections of short duration, children who get few infections which linger for a long time, children who recover quickly after a stormy course, and children who represent any of the other patterns that can be imagined. But within this chaos there is considerable order if the child is allowed to serve as his own control. The individual who is in the upper range of frequency, severity or duration tends strongly to remain there year after year, and the relatively intection-free child remains so. This picture is not altered by tonsillectomy and is little influenced by changing age and diversity of contacts if considered as position in the group frequency rather than in absolute numbers. In our group, before ro years of age there is no sex difference in any factor related to respiratory infection, but something about reaching ro years of age lowers the incidence in the group as a whole, the reduction being slightly greater in boys than in girls. If one considers individual rather than group incidence the higher frequency in adolescent girls seems to result from a few who 
continue with an incidence similar to that in childhood rather than being a general characteristic of the sex.

A search for reasons involved in this extraordinary variability between individuals and consistency within the individual for respiratory and other infections leads to consideration of $\gamma$-globulin concentrations, which represent one universally accepted body defence system. We have been unable so far to demonstrate any simple, easily seen relationship between health history and any of the plasma protein constituents as separated chemically or electrophoretically. This does not argue that such relationships do not exist but only that our methods or our data or both are inadequate so far to express the functional integrations that logically must exist. Considered separately, the plasma proteins offer intriguing opportunities to investigate function and its variability between individuals. Fig. 6 illustrates the usual treatment of such data during the first 3 months of life, showing concentration of

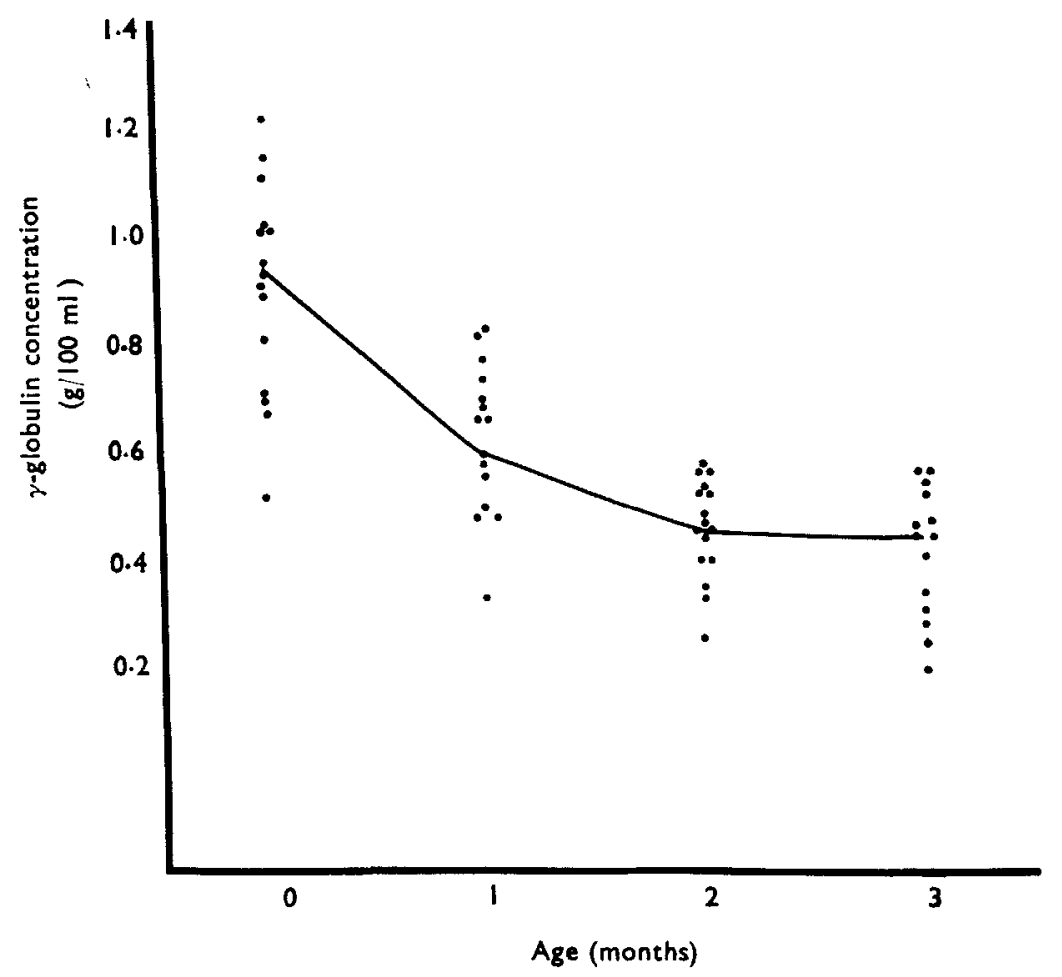

Fig. 6. Concentration of $\gamma$-globulin in the blood of infants from birth to 3 months of age.

$\gamma$-globulin decreasing progressively, and individual determinations grouped closely around the median line. If the values are converted from concentration into amount of circulating $\gamma$-globulin, account being taken of the different sizes of the children for whom these concentrations were obtained and therefore of the demands for synthesis placed upon each child and his success in fulfilling them, the result is the less orderly picture in Fig. 7. This graph was drawn to demonstrate that infants maintain total circulating $\gamma$-globulin levels in spite of metabolizing the molecule steadily during the first 3 months of life, and that the decline in concentration is the 


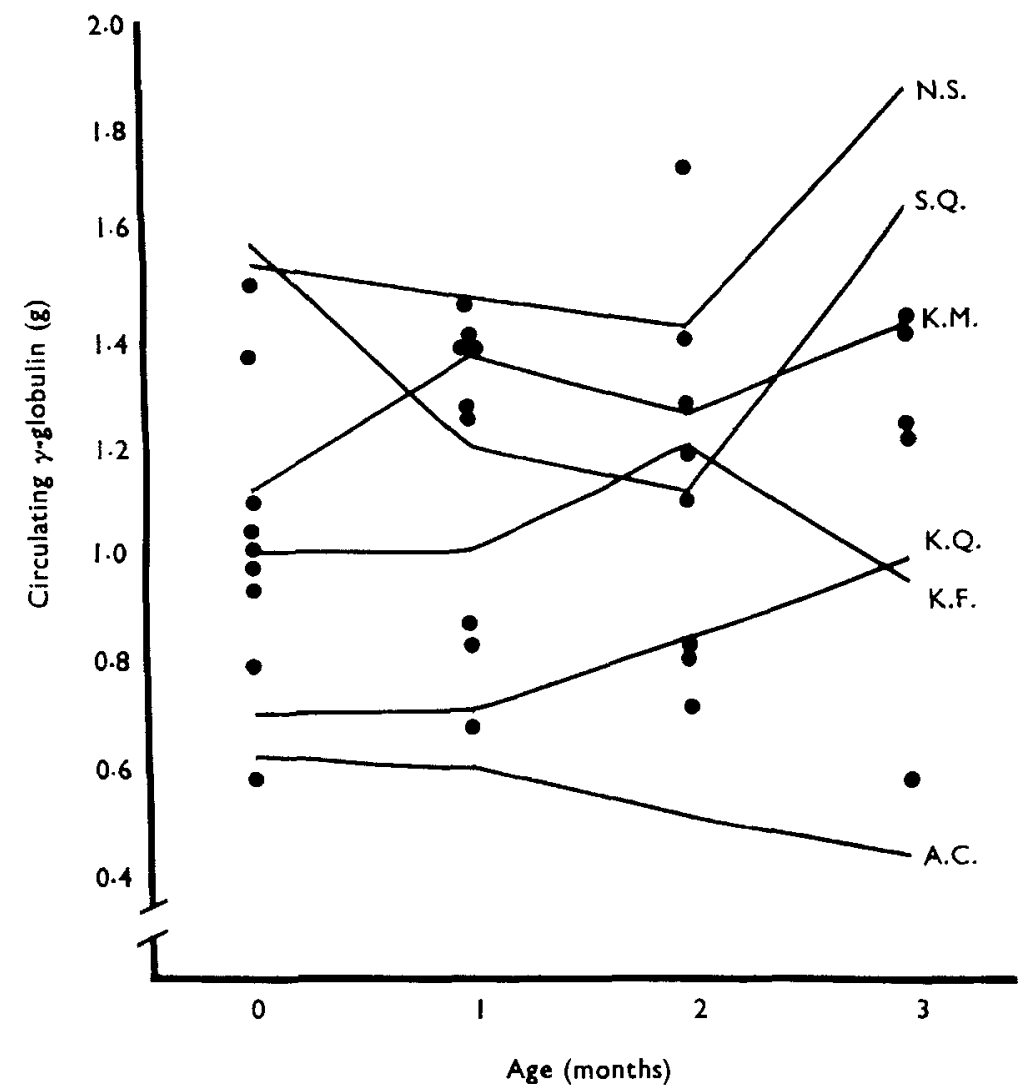

Fig. 7. Total circulating $\gamma$-globulin in infants from birth to 3 months of age. Lines connect values for the same infant. Dots represent values for other infants, each of whom was examined serially.

result of growth of the container rather than failure of synthesis (Trevorrow, 1959). It serves admirably to demonstrate that a smooth group curve can conceal individual functioning rather than elucidate it.

Further, Dr Trevorrow now suspects that individual variation in albumin concentrations in health is not without functional concomitants. The number of subjects studied as yet has been too small for definite conclusions, but association between high albumin concentrations during childhood and early adolescent development has intruded itself too often to be ignored or to support a chance relationship. How such an association functions is a question to worry about while awaiting enough data to document that it exists.

Simple mercy to my fellow man necessitates omission of discussion of individual variation in such characteristics as the cellular elements of the blood, basal and non-basal oxygen consumption, eruption of the deciduous and permanent teeth and electrocardiographic reflections of cardiac conduction and rhythm. It is enough to say that variation exists in these properties as well as in those that have been discussed. Temptation to speculate about interrelationships between variables 
within the individual, either accidental or in terms of cause and effect, must be resisted, since our knowledge is still too tenuous to warrant meaningful guesses. Still, tantalizing clues present themselves, and 20 years from now much that is mystery today is going to be understood and accepted.

I have avoided discussion of nutrition in this group of nutritionists who know so much more in the field than I, a pediatrician, can hope ever to learn. But rather than seem cowardly, and because the subject is intensely interesting, I feel a few remarks in closing are justified. In no part of our study is individual variation more evident than in nutrition. In addition to Miss Beal's published studies (Beal, I953, 1954, 1955, 1956, 1957, 1961; Beal \& Van Buskirk, 1960), I would like to cite some of her unpublished work. A study of dietary iron intake, haemoglobin and red cell values, and physical growth (Beal, Meyers \& McCammon, to be published) re-illustrates the existence of striking variation in dietary iron intake, significant variation in growth rates and meaningful variation in blood values. For purposes of this discussion, the salient finding was the remarkable ability of the individual child to adapt to all these variations and still preserve for himself a stable functional level of haemoglobin. Utilization of ingested iron for haemoglobin synthesis varied from as little as $2 \%$ on very high intakes to as much as $16 \%$ on low intakes in children who maintained haemoglobin levels within the accepted range for health during the first 2 years of life. Nor did rate of growth or therapeutic administration of iron succeed in disrupting the ability to adapt.

Cholesterol and its relationship to dietary fat have been studied in our group. Tentative correlations of the data so far have yielded low negative results, suggesting that during childhood any relationship is doubtful, but if one exists it is inverse. When research findings are diametrically opposite to the weight of medical opinion which has succeeded in modifying the eating habits of an entire nation, one advances one's conclusions in trepidation. It is comforting to have some agreement from a study such as that of the Medical Research Council's Social Medicine Research Unit to support these findings, especially when a totally different population and research plan have been employed (J. W. Marr, i 962 , personal communication).

On that note of gratitude and acceptance of international interdependence I will close. I must not fail, however, to remind both myself and my listeners that there are many more things that are alike in human beings than there are things that are different. The differences are just what make individuals so interesting and provide endless questions lending zest to the attempt to understand.

\section{REFERENCES}

Beal, V. A. (1953). Ұ. Nutr. 50, 223.

Beal, V. A. (1 954). F. Nutr. 53, 499.

Beal, V. A. (1955). F. Nutr. 57, 183 .

Beal, V. A. (1956). $尹$. Nutr. 60, 335 .

Beal, V. A. (I957). Pediatrics, Springfield, 20, 448.

Beal, V. A. (1961). Amer. F. Publ. Hlth, 51, 1 107.

Beal, V. A. \& Van Buskirk, J. J. (I 960). Amer. F. clin. Nutr. 8, 841 .

Boyd, E. (1955). Amer. F. Dis. Child. 89, 332.

Deming, J. (1957). Hum. Biol. 29, 83 .

Hansman, C. F. \& Maresh, M. M. (1961). Amer. J. Dis. Child. ror, 305. 


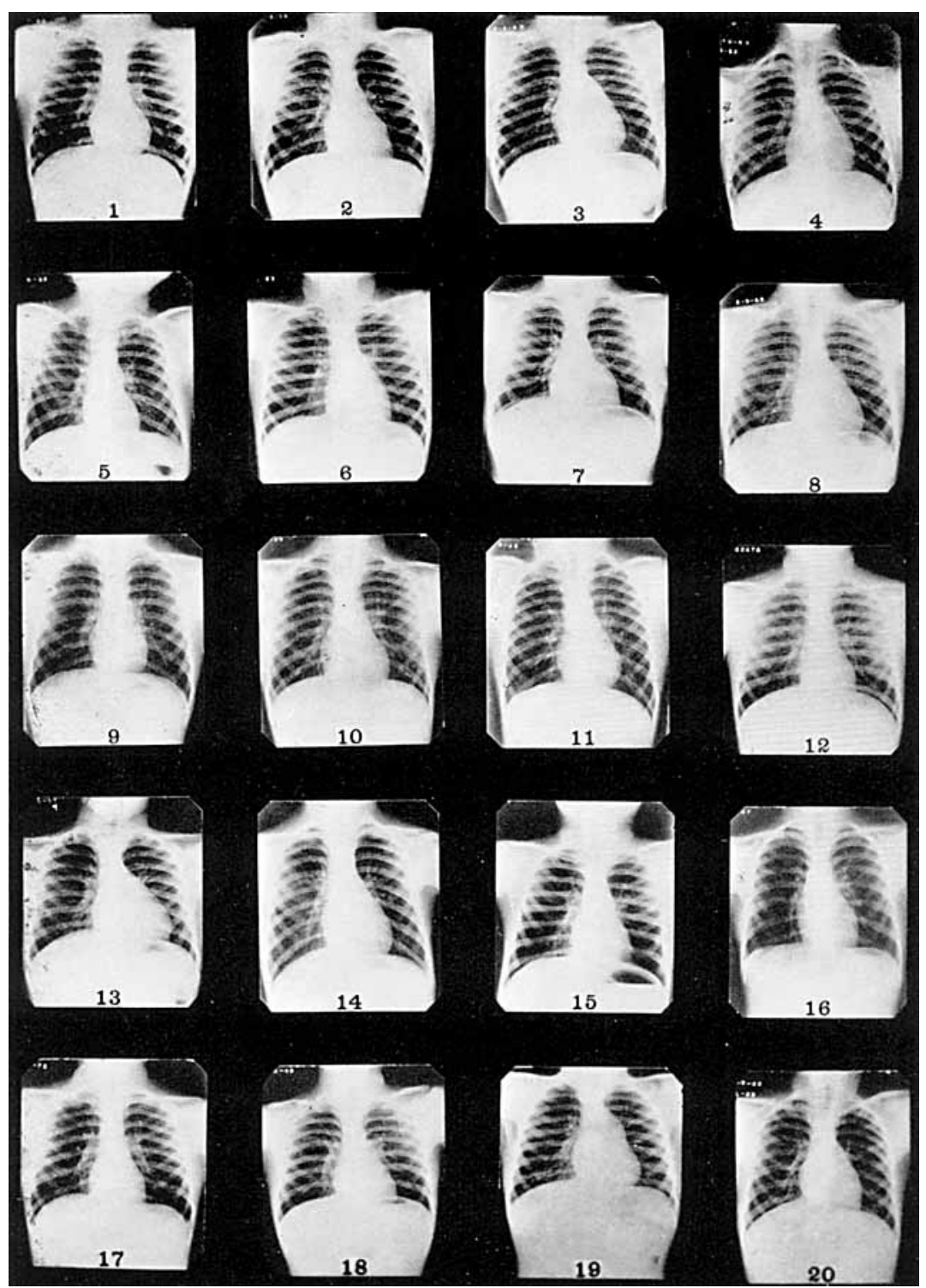

Chest X-ray pictures of twenty healthy boys at 8 years of age, demonstrating variation in heart size and shape between individuals. 


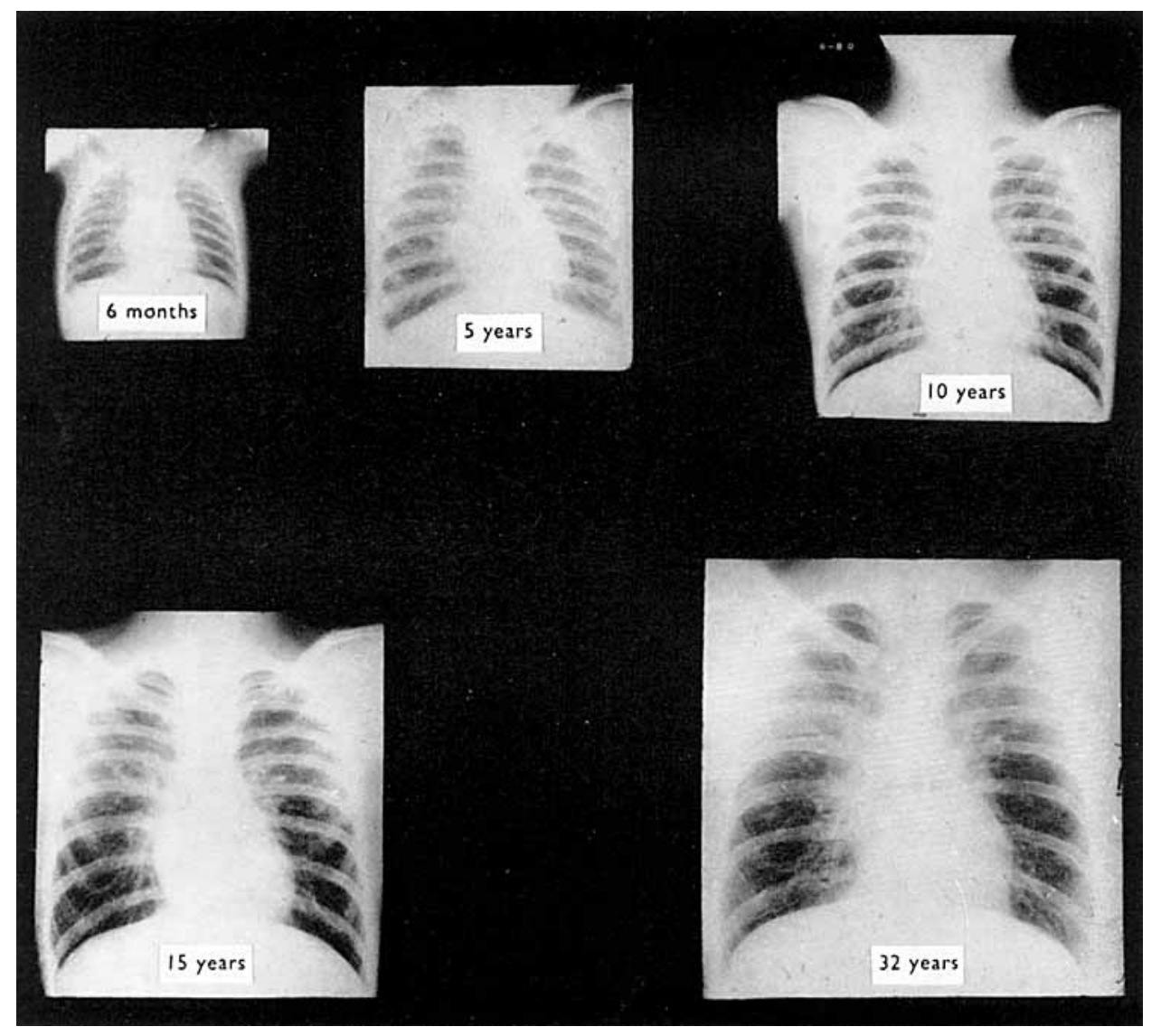

Chest X-ray pictures of one male from 6 months to 32 years, showing consistency of heart shape and lung markings within the individual.

ROBERT W. McCAMMON 


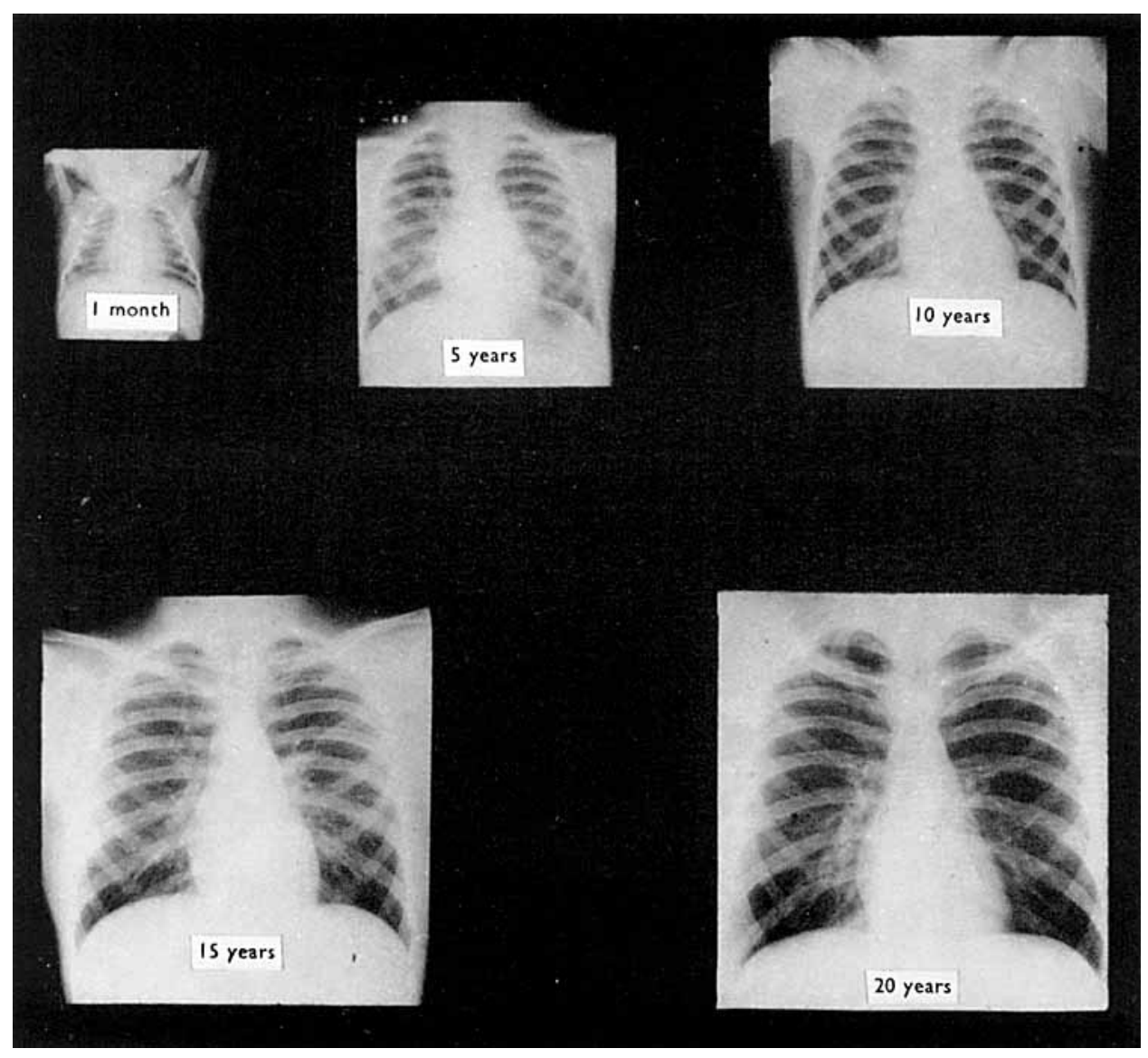

Chest X-ray pictures of one girl from I month to 20 years, showing consistency of heart shape and lung markings in one individual.

\section{ROBERT W. MCCAMMON}


McCammon, R. W. \& Sexton, A. W. (1958). F. Amer. med. Ass. 168, 1440.

Maresh, M. M. (1948). Pediatrics, Springfield, 2, 382 .

Maresh, M. M. (1955). Amer. F. Dis. Child. 89, 725.

Maresh, M. M. (1959). Amer. F. Dis. Child. 98, 27.

Maresh, M. M. (1961). Pediatrics, Springfield, 28, 97 r.

Trevorrow, V. E. (1959). Pediatrics, Springfield, 24, 746.

\title{
Individual variations in energy expenditure and intake
}

\author{
By J. M. Harries, Elizabeth Anne Hobson and Dorothy F. Hollingsworth, \\ Ministry of Agriculture, Fisheries and Food, Great Westminster House, Horseferry \\ Road, London, S.W.1
}

\section{Introduction}

Our interest in this subject arises from a desire for information on individual variation in energy requirements, on the proportion of a population needing more and the proportion needing fewer calories than any stated estimate of its average energy requirements. We should like to be able to compare an array of intakes of energy of individuals with a corresponding array of their energy requirements and so to determine what proportion, if any, of the population might be at risk.

Variations between individuals are to be expected and are known to exist: for example, wide variations in energy intake between individual adults were found in the prewar surveys of Widdowson (1936) on men and of Widdowson \& McCance (1936) on women. Widdowson (1947) also found great variation in the energy intake of children and she discussed possible causes. Rose \& Williams (I96r) have shown wide variations in the calorie intakes of male students of the same weight and, apparently, similar activity. Nevertheless, lack of knowledge on the precise extent of variation between individuals makes it necessary to use mean requirements, with their obvious limitations, in assessing the adequacy of diets. In discussing this unfortunate necessity, Orr \& Leitch (1937-8) reminded their readers that requirements 'are average values so that in practice, especially when individual requirements have to be considered, a margin must be allowed'. Recently, Sukhatme (196r) has drawn attention to the limitations of using average requirements, particularly for assessing inadequate diets or estimating the extent of world food shortage.

In the early studies on energy needs it was usual to measure dietary intake, to consider it in relation to the occupation and other characteristics of the individuals concerned and so to arrive at an estimate of need. For example, Greenwood \& Thompson (I9I7-I 8) considered the energy yield of daily diets and estimates of the cost of certain activities in determining the needs of the 'average man' for an 'average' day's work. Another way of tackling the problem is to measure energy expenditure, and attempts have been made to do it by various means. One way is to sum the energy needed for basal metabolism, the extra energy needed for daily activities and an allowance for the specific dynamic action of foods (cf. Orr \& Leitch, 1937-8). Another way is to record the time spent by individuals on each and all the separate 